\title{
Anthropogenic changes in the surface all-sky UV-B radiation through 1850-2005 simulated by an Earth system model
}

\author{
S. Watanabe ${ }^{1}$, T. Takemura ${ }^{2}$, K. Sudo ${ }^{3}$, T. Yokohata ${ }^{4}$, and H. Kawase ${ }^{1}$ \\ ${ }^{1}$ Japan Agency for Marine-Earth Science and Technology, Yokohama, Japan \\ ${ }^{2}$ Research Institute for Applied Mechanics, Kyushu University, Kasuga, Japan \\ ${ }^{3}$ Graduate School of Environmental Studies, Nagoya University, Nagoya, Japan \\ ${ }^{4}$ National Institute for Environmental Studies, Tsukuba, Japan
}

Correspondence to: S. Watanabe (wnabe@jamstec.go.jp)

Received: 12 January 2012 - Published in Atmos. Chem. Phys. Discuss.: 6 February 2012

Revised: 25 May 2012 - Accepted: 25 May 2012 - Published: 15 June 2012

\begin{abstract}
The historical anthropogenic change in the surface all-sky UV-B (solar ultraviolet: $280-315 \mathrm{~nm}$ ) radiation through 1850-2005 is evaluated using an Earth system model. Responses of UV-B dose to anthropogenic changes in ozone and aerosols are separately evaluated using a series of historical simulations including/excluding these changes. Increases in these air pollutants cause reductions in UVB transmittance, which occur gradually/rapidly before/after 1950 in and downwind of industrial and deforestation regions. Furthermore, changes in ozone transport in the lower stratosphere, which is induced by increasing greenhouse gas concentrations, increase ozone concentration in the extratropical upper troposphere and lower stratosphere. These transient changes work to decrease the amount of UV-B reaching the Earth's surface, counteracting the well-known effect increasing UV-B due to stratospheric ozone depletion, which developed rapidly after ca. 1980. As a consequence, the surface UV-B radiation change between 1850 and 2000 is negative in the tropics and $\mathrm{NH}$ extratropics and positive in the $\mathrm{SH}$ extratropics. Comparing the contributions of ozone and aerosol changes to the UV-B change, the transient change in ozone absorption of UV-B mainly determines the total change in the surface UV-B radiation at most locations. On the other hand, the aerosol direct and indirect effects on UV-B play an equally important role to that of ozone in the NH mid-latitudes and tropics. A typical example is East Asia $\left(25^{\circ} \mathrm{N}-60^{\circ} \mathrm{N}\right.$ and $\left.120^{\circ} \mathrm{E}-150^{\circ} \mathrm{E}\right)$, where the effect of aerosols (ca. $70 \%$ ) dominates the total UV-B change.
\end{abstract}

\section{Introduction}

Excessive solar ultraviolet (UV) radiation reaching the Earth's surface is known to damage animals and plants living on the ground, as well as those living in the water near the surface (see WMO (2007), WMO (2011), UNEP (2006), UNEP (2010) and references therein). Solar UV-B radiation is also known to degrade various organic materials such as plastics, rubber, and paint coatings on cars, ships, and bridges, which shortens their durability. On the other hand, an appropriate exposure to UV-B can be beneficial, for example, sufficient production of vitamin $\mathrm{D}$ in animals requires a certain (slight) level of UV-B exposure. UV-B radiation also sterilizes the surface environment, for example, through exposure of bacilli that float in the atmosphere or live on the ground surface. UV-B radiation is also important in atmospheric chemistry as it produces hydrogen radicals that play central roles in chemical reactions in the troposphere.

Ozone in the stratosphere effectively absorbs UV-B radiation and protects animals and plants on the Earth's surface. The net downward (direct and diffuse) flux of solar UV-B radiation is also strongly reduced in the troposphere due to: (1) Rayleigh scattering by air molecules whose strength rapidly increases with increasing atmospheric density and with decreasing wavelength of light; (2) scattering by cloud droplets, ice crystals, and precipitating materials; (3) scattering and absorption by natural and anthropogenic aerosols; and (4) absorption by tropospheric ozone whose effect can be enhanced by multiple scattering due to the aforementioned scattering processes in the atmosphere. On the other hand, the 
downward diffuse UV-B flux on a bright surface is strongly increased due to enhanced multiple scattering between the surface and air molecules, aerosols, and clouds.

Several modeling studies have estimated the long-term future changes in the surface UV-B radiation associated with projected ozone changes in the stratosphere (Tourpali et al., 2009; Hegglin and Shepherd, 2009). Bais et al. (2011) further considered changes in climatological cloud forcing on erythemal UV. More recently, Watanabe et al. (2011a) and Watanabe and Yokohata (2012) further considered changes in cloud forcing, tropospheric aerosols, tropospheric ozone, and surface albedo. They analyzed future projection simulations through 1960-2100 performed using a comprehensive Earth system model (ESM) including these processes, and highlighted the importance of changes in tropospheric ozone and aerosols that had not been considered in previous studies. An important implication of their studies is that a UV field for either 1960 or 1980, which has been used as a baseline for evaluating the effect of stratospheric ozone changes on the surface UV radiation, is already perturbed due to anthropogenic production of tropospheric ozone and aerosols. To date, no published modeling study focuses on the long-term historical changes in the surface all-sky UV-B radiation from pre-industrial times to the present.

The main goal of the present study is to evaluate the longterm anthropogenic changes in the surface all-sky UV-B radiation through $1850-2005$ by analyzing transient historical simulations of the ESM used by Watanabe et al. (2011a). In particular, responses of the surface all-sky UV-B radiation to anthropogenic changes in ozone and aerosols will be separately evaluated using a series of historical simulations including/excluding these changes. For simplicity, we will refer the all-sky UV-B radiation to UV-B radiation in the remaining of this paper.

\section{Model and experimental designs}

\subsection{Model}

The present study is based on the results of the CMIP5 (Coupled Model Intercomparison Project phase-5; Taylor et al., 2009) simulations of MIROC-ESM-CHEM 2010. Detailed model descriptions and experimental settings of the historical and future simulations are given in Watanabe et al. (2011a) and Watanabe et al. (2011b). MIROC-ESM-CHEM is a comprehensive ESM consisting of coupled atmosphere, ocean, sea-ice, river, land-surface, aerosol, atmospheric chemistry, and ocean and terrestrial carbon cycle models (Watanabe et al., 2011b). In MIROC-ESM-CHEM, the surface UV-B radiation is self-consistently simulated through radiative transfer calculations, because the model predicts ozone chemistry in the stratosphere and troposphere, the amount and optical properties of aerosols and clouds, and the surface reflectivity. The model considers the direct and indirect effects of aerosols on radiative transfer (Takemura et al., 2005). The horizontal resolution of the model is T42 (corresponding to a grid interval of about $300 \mathrm{~km}$ ), and therefore the effects of detailed topography and surface conditions are not considered. MIROC-ESM-CHEM employs mstrnX (Sekiguchi and Nakajima, 2008), a broadband two-stream radiative transfer scheme with a correlated $k$-distribution method, in which the UV-B radiation is calculated for three spectral bands: 278-290 nm, 290-303 nm, and 303-317 nm. MIROC-ESMCHEM outputs the monthly averaged daily dose (accumulative daily exposure) of surface all-sky and clear-sky UV-B radiation as a summation of the aforementioned three spectral bands. The net downward (direct and diffuse) radiative flux of UV-B is included in the daily dose data.

The use of the broadband radiation scheme prevents the evaluation of detailed spectral changes in UV-B, which are required to calculate changes in, for example, erythemal UVB. This is a disadvantage of our study compared to offline UV-B calculations using more detailed radiative transfer schemes (e.g., Bais et al., 2011). On the other hand, the direct on-line simulation of UV-B using an ESM is advantageous over the off-line UV-B calculations from several perspectives. The most important advantage is self-consistency, that is, UV-B is calculated using instantaneous variable fields of ozone, aerosols, clouds, and temperatures simulated in the ESM rather than monthly mean fields typically used in off-line UV-B calculations. In particular, evolution of tropospheric weather systems strongly affects distributions of tropospheric ozone, aerosols, and clouds, on timescales of days, impacting the surface UV-B radiation.

Watanabe et al. (2011b) showed that the model had reasonable performance in reproducing the present-day climatology and historical evolution of dynamical, physical, and chemical fields compared to observations and reanalysis datasets. Watanabe and Yokohata (2012) validated the present-day (1990-2010) climatology of UV-B simulated in MIROCESM-CHEM against spectral observation of UV over East Asia. The seasonal march of monthly mean daily dose of UV-B in the model generally agrees with that observed at two of four stations in Japan, although it is overestimated at the remaining two stations. The model's systematic biases in cloud forcing, i.e., underestimation over land, causes the overestimation of UV-B, while an overestimation of column ozone partly compensates for this effect. Meanwhile, the model qualitatively reproduced observed latitudinal variations in stratospheric ozone and surface UV-B radiation, as well as effects of regional air pollution on UV-B.

\subsection{Experiments}

Table 1 lists the CMIP5 experiments performed using MIROC-ESM-CHEM for this study. Three types of simulation through a historical (1850-2005) period have been performed. The NATo simulation is forced only with historical natural forcing, that is, the reconstructed solar spectral 
Table 1. Summary of CMIP5 experiments for the historical (1850-2005) period used in this study.

\begin{tabular}{llllllll}
\hline Simulation & Solar & Volcano & $\begin{array}{l}\mathrm{CO}_{2} / \mathrm{CH}_{4} / \\
\mathrm{N}_{2} \mathrm{O}\end{array}$ & $\begin{array}{l}\text { ODSs } \\
\text { (halocarbons) }\end{array}$ & $\begin{array}{l}\text { anth. } \mathrm{O}_{3} \\
\text { precursors }\end{array}$ & $\begin{array}{l}\text { anth. aerosol } \\
\text { precursors }\end{array}$ & $\begin{array}{l}\text { land use } \\
\text { change }\end{array}$ \\
\hline NATo & $\mathrm{Y}$ & $\mathrm{Y}$ & & & & & \\
GHGo & & & $\mathrm{Y}$ & $\mathrm{Y}$ & $\mathrm{Y}$ & & $\mathrm{Y}$ \\
HIST & $\mathrm{Y}$ & $\mathrm{Y}$ & $\mathrm{Y}$ & $\mathrm{Y}$ & $\mathrm{Y}$ & $\mathrm{Y}$ & $\mathrm{Y}$ \\
\hline
\end{tabular}

irradiance (Lean et al., 2005) and the optical thickness of volcanic aerosols in the stratosphere (Sato et al., 1993). The GHGo simulation is forced only with historical GHG concentrations including $\mathrm{CO}_{2}, \mathrm{CH}_{4}, \mathrm{~N}_{2} \mathrm{O}$ (Meinshausen et al., 2011), halocarbons (WMO, 2007), and emissions of ozone precursors in the troposphere, e.g., volatile organic compounds, NOx, and CO (Lamarque et al., 2010). In GHGo, we focus on effects of anthropogenic ozone changes in the troposphere and stratosphere on the surface UV-B radiation. HIST is a historical simulation forced with all anthropogenic and natural forcing, i.e., NATo + GHGo + emissions of anthropogenic aerosol precursors + land use change (Watanabe et al., 2011a, b). Actually, surface albedo changes due to land use change are almost negligible in the HIST simulation, and do not alter the surface UV-B radiation. In the present study, we assume that transient responses of the surface UV-B radiation to forcing are additive, so that AERO (三HIST - GHGo) approximately shows direct and indirect effects of anthropogenic changes in aerosols on UV-B when and where UV-B responses to the natural forcing are negligible. This assumption generally holds but sometimes breaks due to effects of climate change on aerosol and ozone concentrations, and of ozone chemistry on aerosol formation. We will attribute the historical changes in the surface UV-B radiation to the contribution of each anthropogenic forcing in the next section.

In addition to the historical simulations, four future projection simulations for the 2006-2100 period have been performed based on the Representative Concentration Pathway (RCP) scenarios (Moss et al., 2010; Meinshausen et al., 2011). Since results of the RCP4.5 and RCP8.5 simulations have already been presented and discussed in Watanabe et al. (2011a), the Appendix of the present paper briefly discusses the long-term behaviors of the surface UV-B radiations in all four scenarios, RCP2.6, RCP4.5, RCP6.0 and RCP8.5, using 1850-1859 as a reference period.

\section{Results}

\subsection{Simulated history of all-sky UV-B}

Figure 1 shows the long-term evolution of the annual mean surface all-sky UV-B radiation averaged over five latitudinal bands, which is shown as a relative change to the 1850 level. The most important finding in the historical period (1850 2005 ) is that the relative change in the surface UV-B radia-

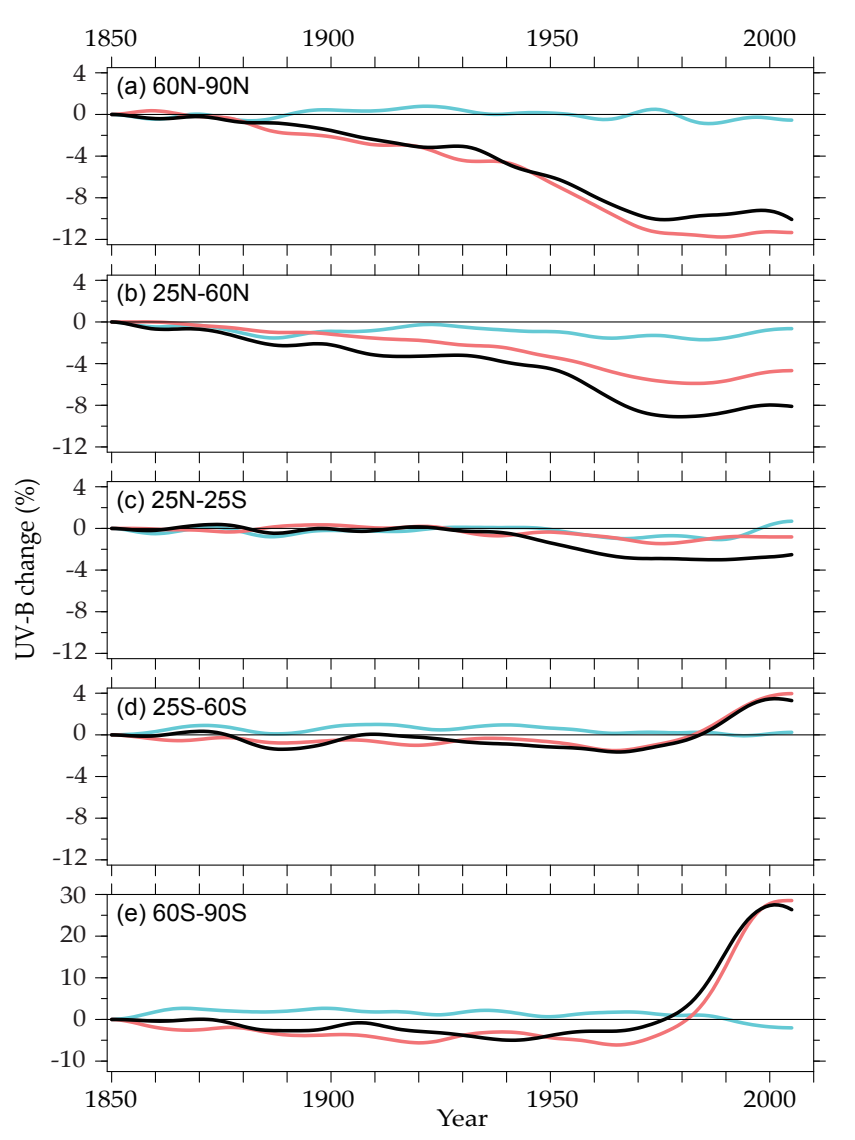

Fig. 1. Long-term evolution of the annual mean surface all-sky UV$\mathrm{B}$ radiation simulated by MIROC-ESM-CHEM. Relative change to the 1850-1859 average is shown. Black curves show the results of the HIST simulation with full historical forcing, while the blue and red curves show the results with natural-only (NATo) and GHGsonly (GHGo) forcing, respectively. In order to focus on the longterm tendency in UV-B, the original time series were smoothed with a 1-2-1 filter applied 60 times. Note that the range of vertical axis in (e) is different from others.

tion is negative in the Northern Hemisphere (NH) and tropics. In the Arctic (Fig. 1a), this decline in the surface UV-B radiation $(-10 \%$ in 2005$)$ is mainly attributable to an increase in ozone absorption of UV-B, because the transient behavior of UV-B in HIST is similar to GHGo and changes in cloud fraction and surface albedo are small (not shown). In the NH mid-latitudes (Fig. 1b), about a half of the UV-B 

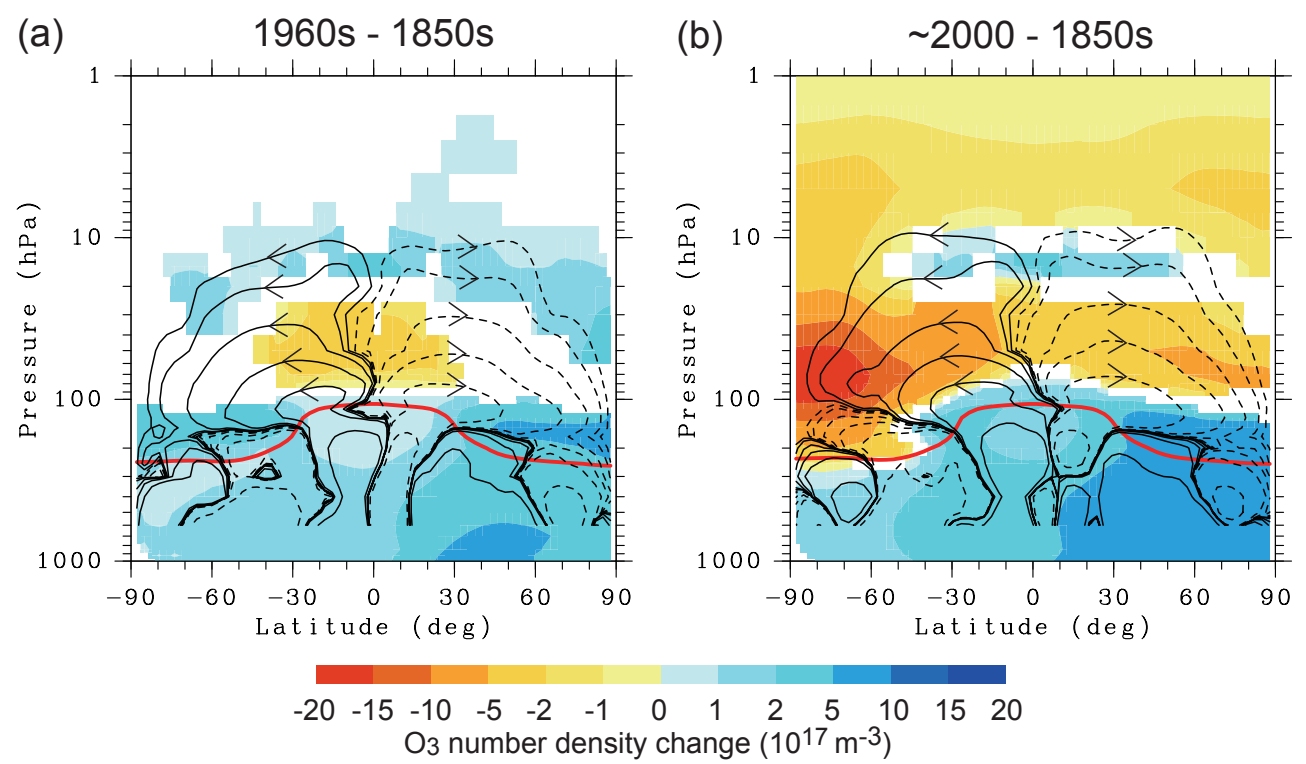

Fig. 2. Changes in the annual and zonal mean ozone number density between (a) the 1960-1969 and the 1850-1859 averages, and (b) 19962005 and the 1850-1859 averages, in the GHGo simulation. The color shading is omitted where the change is less than the $95 \%$ confidence level. The contours show anomalous residual mean mass stream function corresponding to these periods, which indicate an acceleration of the Brewer-Dobson circulation in the lower stratosphere. The red curves show the tropopause diagnosed using the temperature lapse late.

reduction in HIST $(-8 \%$ in 2005$)$ is attributable to an increase in ozone absorption of UV-B (GHGo), while the other half is likely caused by increases in the direct and indirect effects of aerosols (AERO $\equiv$ HIST - GHGo). In the tropics (Fig. 1c), about one-third of the UV-B reduction in HIST $(-3 \%$ in 2005$)$ is attributable to an increase in ozone absorption of UV-B (GHGo), and the remaining two-thirds is caused by the effects of aerosols (AERO $\equiv$ HIST - GHGo). The relative change in the surface UV-B radiation is strongly positive in the Southern Hemisphere (SH) mid-latitudes and Antarctic ( $+3.5 \%$ and $+28 \%$ in 2005 , respectively), which is due to the well known effect of the Antarctic ozone hole decreasing ozone absorption of UV-B (Fig. 1d and e). Geographical distributions of UV-B changes due to these factors will be presented in the next section.

In a transient view, the ozone absorption of UV-B in HIST and GHGo globally increases from 1850 to about 1970. This is mainly due to an increase in production of tropospheric ozone centered in the $\mathrm{NH}$ mid-latitudes, while changes in ozone transport increase (decrease) ozone concentration in the extratropical (tropical) lower stratosphere (Fig. 2a). Acceleration of the Brewer-Dobson circulation in the lower stratosphere increases (decreases) ozone concentration in the extratropics (tropics), because that enhances downward (upward) transport of ozone-rich (poor) air from above (below). This change in the ozone transport in response to increasing GHG concentrations has been commonly seen in previous modeling studies (e.g., Hegglin and Shepherd, 2009). The ozone absorption of UV-B decreases from 1970 to 2000 due to stratospheric ozone depletion caused by an increase in ODS (ozone depleting substance) concentrations, while the increase in tropospheric ozone continues to compensate for this effect (Fig. 2b). The direct and indirect effects of tropospheric aerosols on the surface UV-B radiation gradually increase from 1850 to 1950 in the $\mathrm{NH}$ mid-latitudes, and rapidly increase after 1950 in the NH mid-latitudes and tropics due to enhanced emissions of those precursors mainly from fossil fuel burning and biomass burning (see Watanabe et al., 2011b). Overall, the tropospheric atmosphere in the $\mathrm{NH}$ extratropics and tropics has been strongly polluted by increasing tropospheric ozone and aerosols, and has become less transparent for UV-B.

The present experiments confirm that UV-B changes due to natural forcing (NATo) are generally less than those associated with anthropogenic forcing (HIST and GHGo), and are primarily caused by changes in ozone absorption of UV$\mathrm{B}$ in the lower stratosphere. These are caused by anomalous ozone transport and chemistry effects indirectly induced by volcanic aerosols in the stratosphere. These effects slightly decrease (increase) the surface UV-B radiation in the NH (SH). Since the present paper focuses on anthropogenic effects on the long-term UV-B changes, these natural variations would be studied in a separate paper.

\subsection{Anthropogenic forcing on UV-B}

Here, we focus on geographical distributions of UV-B changes between the present (1996-2005) and pre-industrial (1850-1859) periods, and decompose the UV-B changes into responses to various anthropogenic forcing. 


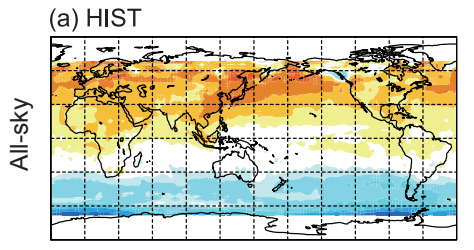

II

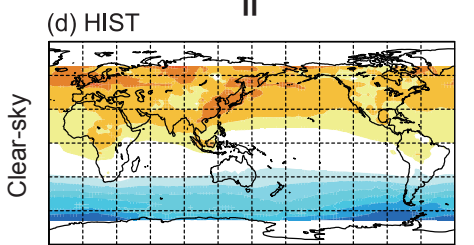

$+$

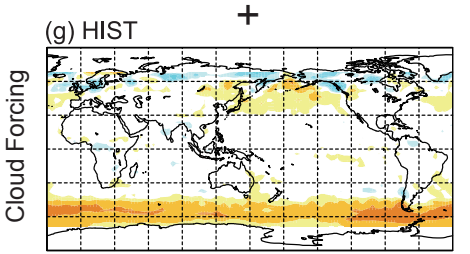

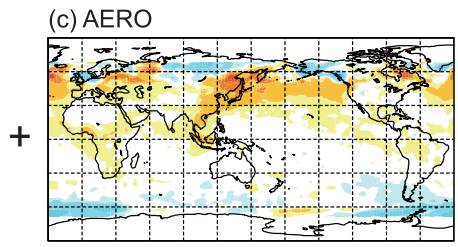

II

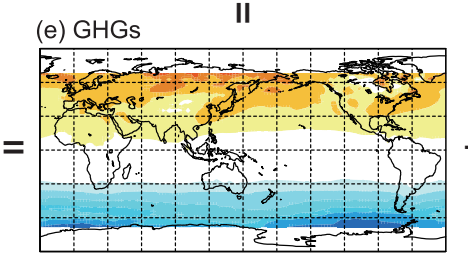

$+$
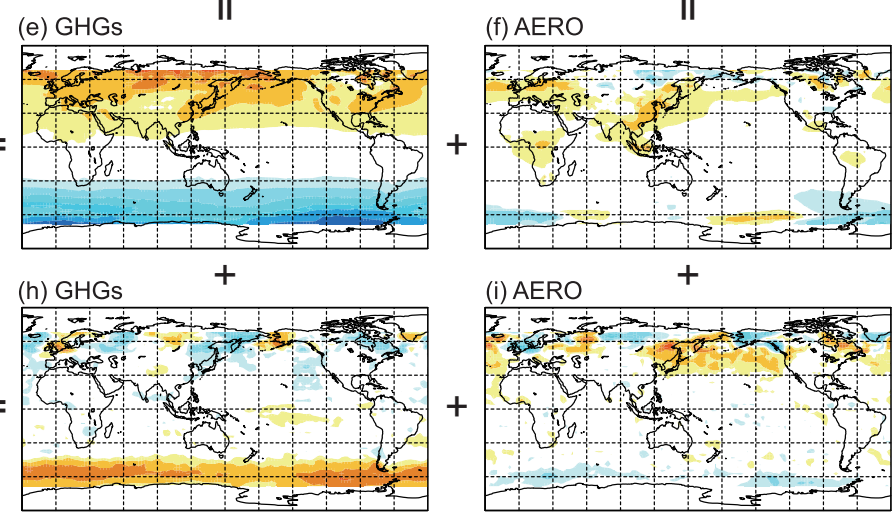

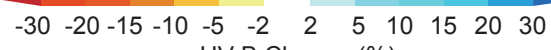

UV-B Change (\%)

Fig. 3. Relative changes in the annual mean surface all-sky UV-B radiation between the present (1996-2005) and pre-industrial (18501859) periods. As schematically illustrated, the all-sky UV-B changes in the HIST simulation (top left) are approximately decomposed into responses to GHGs forcing (top centre) and aerosol forcing (top right), as well as due to clear-sky processes (middle row) and cloud forcing (bottom row).

Figure 3a shows relative differences in the annual mean surface UV-B radiation between the present and preindustrial periods in the HIST simulation. Since UV-B changes due to natural forcing between these two periods are negligible (Fig. 1), the UV-B changes in HIST can be decomposed into responses to anthropogenic forcing due to GHGs and aerosols, respectively. Figure $3 b$ shows UV-B changes in the GHGo simulation consisting of responses of UV$\mathrm{B}$ to anthropogenic changes in ozone, surface albedo, and cloud forcing. Figure $3 \mathrm{c}$ shows UV-B changes in the (HIST - GHGo) simulations, approximately showing responses of UV-B to anthropogenic changes in direct and indirect effects of aerosols. Using all-sky and clear-sky UV-B data, contributions of clear-sky part (Fig. 3d-f) and cloud forcing (Fig. 3gi) to the all-sky UV-B changes can be separately evaluated for each case. In Figure 3, the statistical significance of UV-B changes generally exceeds the $95 \%$ level where the relative changes are greater than $2 \%$, as indicated by colour shading. The UV-B changes at latitudes higher than $75^{\circ} \mathrm{N}$ and $\mathrm{S}$ are omitted for clarity in the tropics and mid-latitudes, which are the regions of focus. Figure $3 e$ shows effects of anthropogenic changes in ozone and surface albedo on the surface UV-B radiation. The effect of surface albedo reductions with global warming, which decreases the surface UV-B radiation, are generally small except around the Arctic, so that the effect of ozone changes are predominant all over the world. A longitudinally quasi-uniform increase in UV-B in the SH ex- tratropics is caused by the stratospheric ozone depletion. It enlarges with increasing latitude associated with the Antarctic ozone hole. A reduction in UV-B in the NH subtropics and mid-latitudes exhibits regional structures associated with increasing industrial productions and transport of tropospheric ozone around and downwind of Europe, Asia, and North America. Furthermore, changes in ozone transport in the $\mathrm{NH}$ lowermost stratosphere partly contribute to the reduction in UV-B (Fig. 2b).

Figure $3 \mathrm{f}$ approximately shows the direct effect (reflection, absorption, and multiple scattering in ozone-containing air) of aerosols on the surface UV-B radiation. Note that UV$\mathrm{B}$ changes in the high latitudes of both hemispheres do not show the aerosol direct effect, but reflect slight differences in surface albedo changes between HIST and GHGo. The aerosol direct effect significantly reduces the surface UV$B$ radiation around and downwind of industrial and deforestation regions with fossil fuel burning and biomass burning (Europe, Asia, central Africa and Amazon), and is negligible in the SH. Watanabe et al. (2011b) described actual aerosol changes and direct effect in the HIST simulation, although they did not focus on aerosol effects on UV-B. Figure $3 \mathrm{~d}$ shows the summation of the ozone effects (Fig. 3e) and aerosol effects (Fig. 3f).

Figure 3 h shows responses of the surface UV-B radiation to changes in cloud forcing (reflection and multiple scattering in ozone-containing air) associated with past climate change 

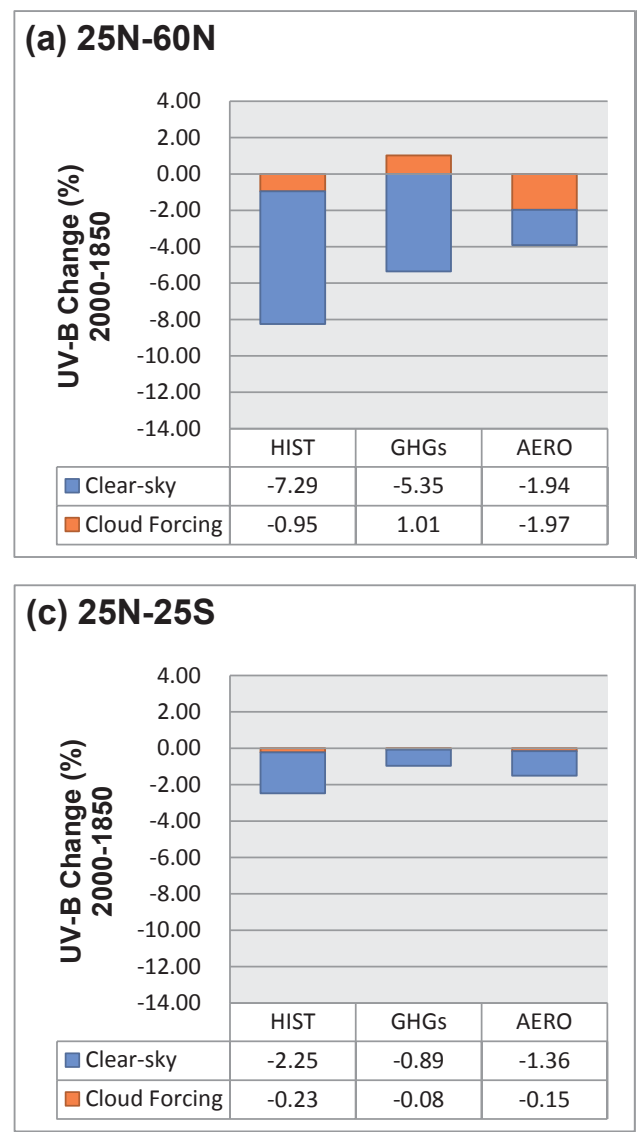
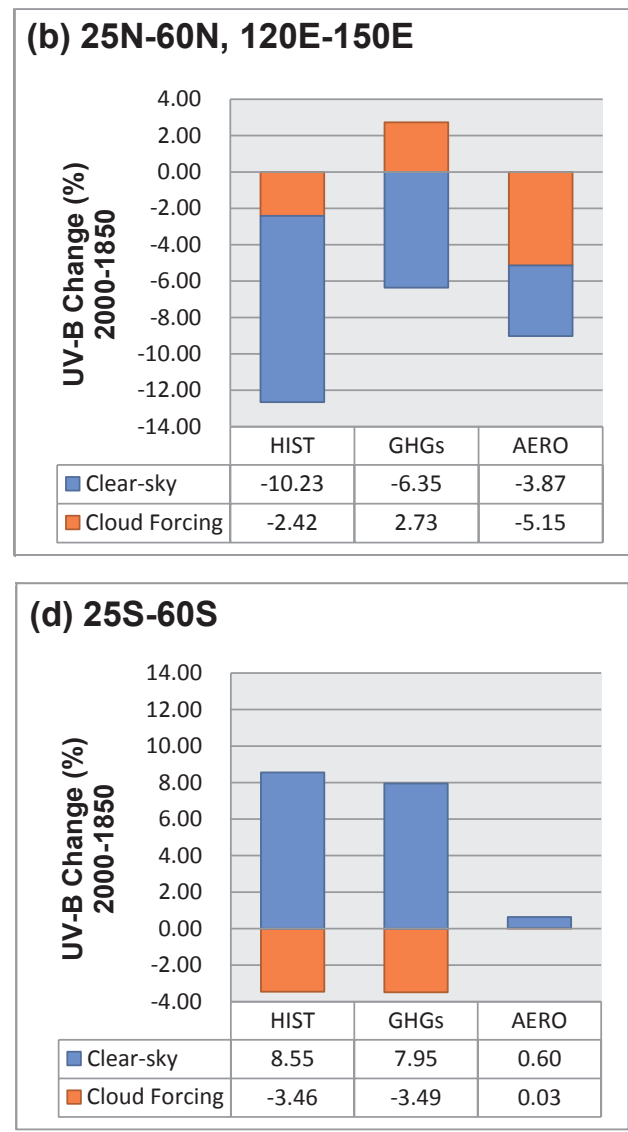

Fig. 4. Attribution of UV-B responses to each anthropogenic forcing (see text).

due to GHG increases. A longitudinally quasi-uniform reduction in UV-B over the Antarctic Ocean is mainly caused by increases in cloud albedo, which is often seen in the state-of-art climate models (Yokohata et al., 2008). As of the secondary importance, clouds over the Antarctic Ocean, even if they are not changed, shade UV-B which is increased due to the development of Antarctic ozone hole. Patterned, longitudinally not uniform UV-B changes in the NH mid- and high latitudes reflect changes in cloud distribution, which are likely to be associated with changes in tropospheric circulation.

Figure $3 \mathrm{i}$ approximately shows the aerosol indirect effect on the surface UV-B radiation. Significant increases in cloud forcing around the North Pacific and North Atlantic reduce the surface UV-B radiation. These regions were very clean in preindustrial times and became gradually polluted by anthropogenic aerosols, increasing cloud fraction and cloud albedo with time due to the first and second indirect effects considered in the model.

Figure 4a summarizes the abovementioned analysis for the NH mid-latitudes. The increase in ozone absorption primarily decreases the surface UV-B radiation by $-5.35 \%$, while a slight reduction in cloud forcing due to climate change partly compensates for this effect by $+1.01 \%$. The increase in aerosol direct and indirect effects decreases the surface UV-B radiation by about $-2 \%$ for each. In total, the changes in clear-sky processes consisting of the ozone absorption and aerosol direct effect decrease the surface UV-B radiation by $-7.29 \%$, and the changes in the cloud forcing consisting of the cloud responses to climate change and aerosols decrease UV-B by $-0.95 \%$. As was seen in Fig. 3, the distribution of these UV-B changes is not longitudinally uniform. Figure $4 \mathrm{~b}$ shows similar statistics to Figure $4 \mathrm{a}$, but focussed on the most polluted region of the world in 2000 surrounding Japan $\left(120^{\circ} \mathrm{E}-150^{\circ} \mathrm{E}\right.$ and $\left.25^{\circ} \mathrm{N}-60^{\circ} \mathrm{N}\right)$. In this region, the total UV-B reduction effect of aerosols $(-3.87 \%-$ $5.15 \%=-9.02 \%)$ dominates that of ozone $(-6.35 \%)$.

In the tropics, changes in cloud forcing are negligible, and increases in the aerosol direct effect $(-1.36 \%)$ and ozone absorption $(-0.89 \%)$ reduce the surface UV-B radiation by $-2.25 \%$ (Fig. 4c). The effect of aerosols is actually negligible in the SH mid-latitudes as mentioned earlier, and the reduction in ozone absorption associated with the Antarctic ozone hole increases the surface UV-B radiation by about $+8 \%$ (Fig. $4 \mathrm{~d}$ ). The effect of the reduction in cloud forcing partly compensates for this effect by about $-3.5 \%$. Note that both ozone and cloud changes have large latitudinal gradient in the SH mid-latitudes (Fig. 3e and h). 


\section{Concluding remarks}

The historical anthropogenic changes in the surface allsky UV-B radiation through 1850-2005 are evaluated by analyzing the CMIP5 transient historical simulations performed with MIROC-ESM-CHEM. The responses of the surface UV-B radiation to anthropogenic changes in ozone and aerosols are separately evaluated using a series of historical simulations including/excluding these changes. Due to the increasing emissions of tropospheric ozone and aerosol precursors, the transparency of the troposphere to UV-B gradually (rapidly) decreases before (after) 1950 in and downwind of the industrial and deforestation regions, which are mostly located in the NH mid-latitudes and tropics. Furthermore, the changes in ozone transport in the lower stratosphere, which is induced by increasing GHG concentrations, increase ozone concentration in the extratropical upper troposphere and lower stratosphere. These transient changes work to decrease the amount of UV-B reaching the Earth's surface, counteracting the well-known effect increasing UV$B$ radiation due to stratospheric ozone depletion, which developed rapidly through 1980-2000. As a result, the surface UV-B radiation change between 2000 and 1850 is negative in the tropics and $\mathrm{NH}$ extratropics and positive in the SH extratropics. Comparing the contributions of ozone and aerosol changes to the UV-B change, the transient change in ozone absorption of UV-B mainly determines the total change in the surface UV-B radiation at most locations. In addition, the aerosol direct and indirect effects on UV-B play an important role in the $\mathrm{NH}$ mid-latitudes and tropics. A typical example is East Asia $\left(25^{\circ} \mathrm{N}-60^{\circ} \mathrm{N}\right.$ and $\left.120^{\circ} \mathrm{E}-150^{\circ} \mathrm{E}\right)$, where the effect of aerosols (ca. 70\%) dominates the total UV-B change.

The simulated long-term changes in the surface UV-B radiation are likely to suffer from several types of uncertainties. These may include model uncertainties, such as: physical and chemical processes associated with ozone, aerosols, and clouds; dynamical fields that affect transport of ozone and aerosols, and distribution of clouds through moisture transport and static stability changes; and responses of the physical, chemical and dynamical systems to various kinds of natural and anthropogenic forcing. Furthermore, uncertainties in each historical forcing, which are typically reconstructed based on limited records, may have the strongest impact on the simulation results. In addition to these uncertainties in the modeling framework, a lack of surface UV-B observations before the 1990s prevents the thorough validation of the historical simulation results.

We cannot fully address each of these issues in the present paper, and further detailed evaluations of the model are underway under the international frameworks of multi-model intercomparison projects with observations, such as CMIP5, AeroCom (Aerosol Comparisons between Observations and Models), and ACCMIP (Atmospheric Chemistry and Climate Model Intercomparison Project). Moreover, multi-ESM comparisons of ozone, aerosol, clouds, and (if possible) UV-

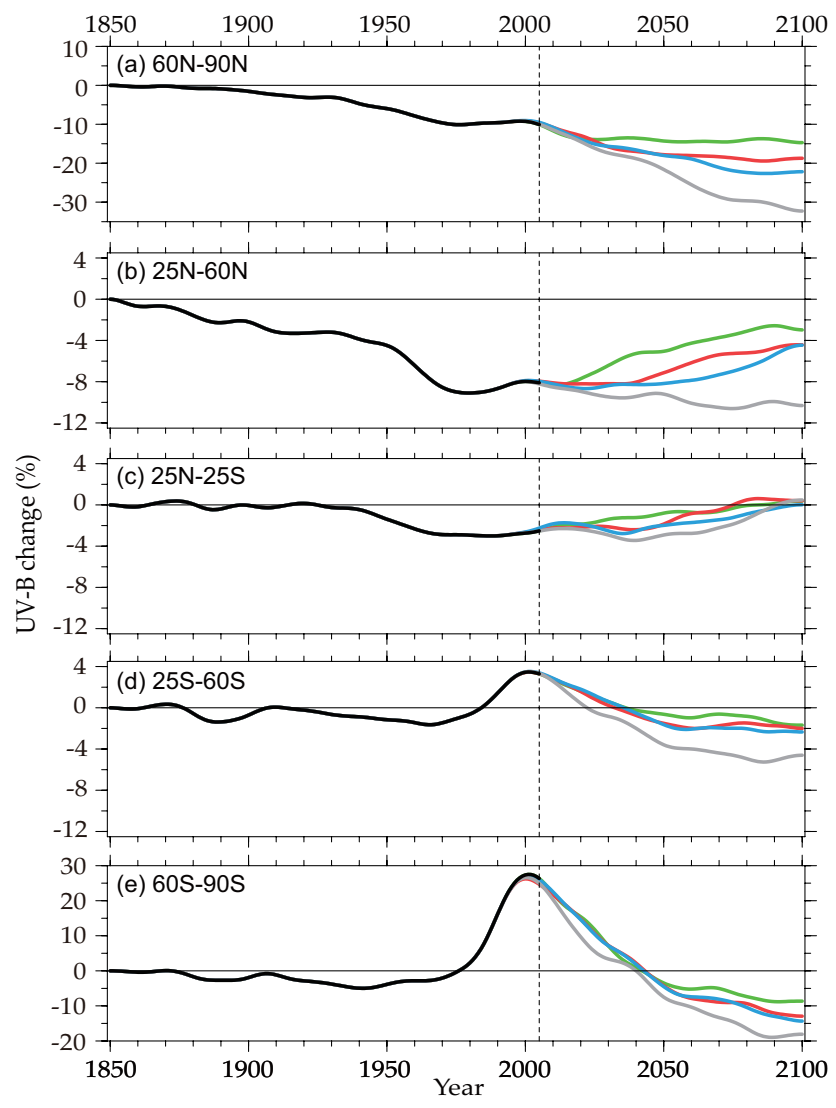

Fig. A1. Long-term evolution of the annual mean surface allsky UV-B radiation simulated by MIROC-ESM-CHEM. Relative change to the 1850-1859 average is shown. Black curves show the results of the HIST simulation with full historical forcing. Green: RCP2.6, Red: RCP4.5, Blue: RCP6.0, and Gray: RCP8.5 simulations. In order to focus on the long-term tendency in UV-B, the original time series were smoothed with a 1-2-1 filter applied 60 times. Note that the range of vertical axes in (a) and (e) is different from others.

B fields may be useful to estimate the uncertainty in model's responses to various historical forcing.

\section{Appendix A}

The projected future evolution of the surface all-sky UV-B radiation from 2006 to 2100 depends on the latitudinal bands and RCP scenarios (Fig. A1). The UV-B increases with time in the NH mid-latitudes in RCP2.6, RCP4.5, and RCP6.0, and in the tropics in all RCPs. At these latitudes, UV-B gradually recovers to approach its pre-industrial level. This is mainly due to the recovery of air quality, i.e., reductions in tropospheric ozone and aerosols, presumed in the future RCP scenarios. The reduction in aerosols accompanies reductions in cloud forcing through the indirect effect, further increasing the surface UV-B radiation. The UV-B radiation decreases at 
other latitudes with cleaner skies: the Arctic and SH extratropics. The ozone hole recovery (surface albedo reduction) is obvious in the SH extratropics (Arctic) in the first half of this century, while ozone increases due to transport changes in the lower stratosphere dominate in the second half of this century (see Watanabe et al., 2011a for details of the RCP4.5 and RCP8.5 simulations).

The higher radiative forcing scenario with higher GHG concentrations generally results in less UV-B radiation. This dependency is due to multiple processes affecting the surface UV-B radiation, which are detailed in Watanabe et al. (2011a). Here, we recall a brief summary of their analysis. The higher GHG concentration leads to warmer surface temperatures with less surface albedo, which reduces downward diffuse flux of UV-B in the polar region. The higher GHG concentration also accompanies the stronger BrewerDobson circulation leading to higher ozone concentration in the extratropical upper troposphere and lower stratosphere, which causes stronger absorption of UV-B. The tropospheric ozone precursors and aerosol precursors are presumed to decrease in all RCP scenarios, while the reductions occur more slowly in the higher radiative forcing scenario, resulting in a less transparent sky for UV-B in a given year. The particularly lower surface UV-B radiation in the NH mid-latitude of the RCP8.5 simulation is partly caused by the continuous increase in tropospheric ozone throughout the 21 st century, which is induced by the continuous increase of methane concentration presumed in this scenario (Kawase et al., 2011).

Acknowledgements. The authors would like to thank three anonymous referees to provide useful comments to improve the manuscript. They also thank Team-MIROC for their support and encouragement throughout the present study. This study was supported by the Innovative Program of Climate Change Projection for the 21st Century, MEXT, Japan. The numerical simulations in this study were performed using the Earth Simulator, and figures were drawn using GTOOL and the GFD-DENNOU Library.

Edited by: L. M. Russell

\section{References}

Bais, A. F., Tourpali, K., Kazantzidis, A., Akiyoshi, H., Bekki, S., Braesicke, P., Chipperfield, M. P., Dameris, M., Eyring, V., Garny, H., Iachetti, D., Jöckel, P., Kubin, A., Langematz, U., Mancini, E., Michou, M., Morgenstern, O., Nakamura, T., Newman, P. A., Pitari, G., Plummer, D. A., Rozanov, E., Shepherd, T. G., Shibata, K., Tian, W., and Yamashita, Y.: Projections of UV radiation changes in the 21st century: impact of ozone recovery and cloud effects, Atmos. Chem. Phys., 11, 7533-7545, doi:10.5194/acp-11-7533-2011, 2011.

Hegglin, M. I. and Shepherd, T. G.: Large climate-induced changes in ultraviolet index and stratosphere-to-troposphere ozone flux, Nat. Geosci., 2, 687-691, doi:10.1038/Ngeo604, 2009.

Kawase, H., Nagashima, T., Sudo, K., and Nozawa, T.: Future changes in tropospheric ozone under Representative Concen- tration Pathways (RCPs), Geophys. Res. Lett., 38, L05801, doi:10.1029/2010GL046402, 2011.

Lamarque, J.-F., Bond, T. C., Eyring, V., Granier, C., Heil, A., Klimont, Z., Lee, D., Liousse, C., Mieville, A., Owen, B., Schultz, M. G., Shindell, D., Smith, S. J., Stehfest, E., Van Aardenne, J., Cooper, O. R., Kainuma, M., Mahowald, N., McConnell, J. R., Naik, V., Riahi, K., and van Vuuren, D. P.: Historical (1850-2000) gridded anthropogenic and biomass burning emissions of reactive gases and aerosols: methodology and application, Atmos. Chem. Phys., 10, 7017-7039, doi:10.5194/acp10-7017-2010, 2010.

Lean, J., Rottman, G., Harder, J., and Kopp, G.: SORCE contributions to new understanding of global change and solar variability, Solar Phys., 230, 27-53, 2005.

Meinshausen, M., Smith, S., Calvin, K. V., Daniel, J. S., Kainuma, M., Lamarque, J.-F., Matsumoto, K., Montzka, S. A., Raper, S. C. B., Riahi, K., Thomson, A. M., Velders, G. J. M., and van Vuuren, D.: The RCP Greenhouse Gas Concentrations and their extension from 1765 to 2500 , Clim. Change, 109, 213-241, doi:10.1007/s10584-011-0156-z, 2011.

Moss, R. H., Edmonds, J. A., Hibbard, K. A., Manning, M. R., Rose, S. K., van Vuuren, D. P., Carter, T. R., Emori, S., Kainuma, M., Kram, T., Meehl, G. A., Mitchell, J. F. B., Nakicenovic, N., Riahi, K., Smith, S. J., Stouffer, R. J., Thomson, A. M., Weyant, J. P., and Wilbanks, T. J.: The next generation of scenarios for climate change research and assessment, Nature, 463, 747-756, doi:10.1038/nature08823, 2010.

Sato, M., Hansen, J. E., McCormick, M. P., and Pollack, J. B.: Stratospheric aerosol optical depth, 1850-1990, J. Geophys. Res., 98, 22987-22994, 1993.

Sekiguchi, M. and Nakajima, T.: A k-distribution based radiation code and its computational optimization for an atmospheric general circulation model, J. Quant. Spectrosc. Radiat. Transfer, 109, 2779-2793, 2008.

Takemura, T., Nozawa, T., Emori, S., Nakajima, T. Y., and Nakajima, T.: Simulation of climate response to aerosol direct and indirect effects with aerosol transport-radiation model. J. Geophys. Res., 110, D02202, doi:10.1029/2004JD005029, 2005.

Taylor, K. E., Stouffer, R. J., and Meehl, G. A.: A summary of the CMIP5 experimental design, lavailable at: http://cmip-pcmdi. llnl.gov/cmip5/experiment_design.html?submenuheader=1, ast access: 8 April 2010, 2009.

Tourpali, K., Bais, A. F., Kazantzidis, A., Zerefos, C. S., Akiyoshi, H., Austin, J., Brühl, C., Butchart, N., Chipperfield, M. P., Dameris, M., Deushi, M., Eyring, V., Giorgetta, M. A., Kinnison, D. E., Mancini, E., Marsh, D. R., Nagashima, T., Pitari, G., Plummer, D. A., Rozanov, E., Shibata, K., and Tian, W.: Clear sky UV simulations for the 21 st century based on ozone and temperature projections from Chemistry-Climate Models, Atmos. Chem. Phys., 9, 1165-1172, doi:10.5194/acp-9-1165-2009, 2009.

UNEP: Environmental effects of ozone depletion and its interaction with climate change: 2006 assessment, United Nations Environment Programme (UNEP), Nairobi, 206, 2006.

UNEP: Environmental effects of ozone depletion and its interaction with climate change: 2010 assessment, United Nations Environment Programme (UNEP), Nairobi, 278, 2010.

Watanabe, S., Sudo, K., Nagashima, T., Takemura, T., Kawase, H., and Nozawa, T.: Future Projections of Surface UV-B 
in a Changing Climate, J. Geophys. Res., 116, D16118, doi:10.1029/2011JD015749, 2011a.

Watanabe, S., Hajima, T., Sudo, K., Nagashima, T., Takemura, T., Okajima, H., Nozawa, T., Kawase, H., Abe, M., Yokohata, T., Ise, T., Sato, H., Kato, E., Takata, K., Emori, S., and Kawamiya, M.: MIROC-ESM 2010: model description and basic results of CMIP5-20c3m experiments, Geosci. Model Dev., 4, 845-872, doi:10.5194/gmd-4-845-2011, 2011 b.

Watanabe, S. and Yokohata, T.: Future Increase of All-sky UV-B over Asia Projected by an Earth System Model., J. Metorol. Soc. Jpn., 90A, 297-306, doi:10.2151/jmsj.2012-A15, 2012.

World Meteorological Organization (WMO): Scientific Assessment of Ozone Depletion: 2006, Rep. 50, Global Ozone Research and Monitoring Project, World Meteorol. Organ., Geneva, Switzerland, 2007.
World Meteorological Organization (WMO): Scientific Assessment of Ozone Depletion: 2010, Rep. 52, Global Ozone Research and Monitoring Project, World Meteorol. Organ., Geneva, Switzerland, 2011.

Yokohata, T., Emori, S., Nozawa, T., Ogura, T., Yukimoto, S., Suzuki, T., Tsushima, Y., Kawamiya, M., Abe-Ouchi, A., Hasumi, H., Sumi, A., and Kimoto, M.: Comparison of equilibrium and transient responses to $\mathrm{CO}_{2}$ increase in eight state-of-theart climate models., Tellus A, 60, 946-961, doi:10111/j.16000870.2008.00345.x, 2008 